\title{
ANÁLISE DO GRAU DE INSTRUÇÃO DOS ASSISTIDOS QUE POSSUEM MEDIDA EDUCATIVA NO PATRONATO PENITÊNCIÁRIO DE LONDRINA
}

\author{
Alinne Garcia Cavagnari \\ Nayara Ap. dos Santos Almeida \\ Juliana Bicalho de Carvalho Barrios
}

\section{RESUMO}

O presente trabalho tem como objetivo analisar o grau de escolaridade dos sujeitos que possuem como condição penal a Medida Educativa no qual irá dar inicio ao seu processo de ressocialização por meio do acompanhamento do Pedagogo situado no Patronato Penitenciário de Londrina. Esta pesquisa se configura por ser uma pesquisa quantitativa, baseada em dados obtidos pelo próprio Patronato, no qual foram analisados e tabulados para a busca de novas constatações. O Patronato Penitenciário de Londrina se configura como sendo a única Instituição Publica voltada para o processo de ressocialização de sujeitos que já cumpriram uma demanda penal em regime fechado e adquirem o direito de cumprir em regime aberto o restante de sua pena. A Medida Educativa se constitui como uma das alternativas de ressocialização deste sujeito, onde proporciona para o mesmo o contato com a educação por meio de cursos ou mesmo a própria Educação Formal. Assim, esta pesquisa adquire um caráter investigativo de buscar revelar se o grau de escolaridade dos sujeitos que cumprem Medida Educativa obtém relação com a incidência de novos delitos.

Palavras-Chave: Ressocialização; Grau de Instrução, Medida Educativa.

\section{INTRODUÇÃO}

A educação corresponde a um elemento de direito e fundamental para todos os cidadãos. É por meio desta que os sujeitos adquirem e se apropriam dos bens culturais de uma sociedade e se desenvolvem na medida de sua apropriação, sendo, então, um elemento, além do próprio direito dos sujeitos, um dever social. De acordo com a Lei de Diretrizes e Bases - LDBEN (BRASIL, 1996), em seu artigo 2º a educação é um dever da família e do Estado, que possui como finalidade o pleno desenvolvimento do educando, preparo para o desenvolvimento e a cidadania, além da própria qualificação para o trabalho. Deste modo, a educação é um direito de todos os sujeitos, bem como elemento chave para o desenvolvimento social, sendo que a discussão ora proposta, cujo foco é o processo de ressocialização de sujeitos em final de pena ou que estão no cumprimento de penas alternativas, tem, na educação e, portanto, no direito à educação, um elemento importante em seu processo de ressocialização.

Por meio da educação, o processo de ressocialização dos sujeitos se inicia. Logo, a educação é um mecanismo a ser utilizado por todos neste processo, bem como, também, indivíduos que possuem alguma discordância com a lei. Assim, o processo de ressocialização originou-se a fim de conscientizar estes sujeitos de suas ações pelo próprio contato social e inseri-los novamente na sociedade, onde este processo ocorre 


\section{SEMINÁRIO DE PESQUISA EM CIÊNCIAS HUMANAS - SEPECH \\ Humanidades, Estado e desafios didático-científicos \\ Londrina, 27 a 29 de julho de 2016}

no Patronato Penitenciário de Londrina, em formas de medidas educativas, a fim de buscar a diminuição da ocorrência de novos delitos.

\section{PATRONATO PENITENCIÁRIO DE LONDRINA}

O Patronato Penitenciário de Londrina (PLDA) foi criado no dia 11 de Abril de 2001 através da iniciativa do Promotor Dr. Nilton Bus, se configurando por ser uma Instituição de ordem Pública, que atende os sujeitos que cometeram algum crime e foram encaminhados para cumprir sua pena em regime fechado, porém, o PLDA só atenderá estes mesmos sujeitos, quando ocorrer a transição de regime, saindo do regime fechado para o regime aberto ou ainda, do semi-aberto, para o aberto. Logo, tem como objetivo, proporcionar o início do processo de ressocialização perante a sociedade.

De acordo com a Lei $n^{\circ} 7.210$, de 11 de julho de 1984, no capítulo VII cabe ao Patronato:
Art. 78. O Patronato público ou particular destina-se a prestar assistência aos albergados e aos egressos (artigo 26).
Art. 79. Incumbe também ao Patronato:
I - orientar os condenados à pena restritiva de direitos;
II - fiscalizar o cumprimento das penas de prestação de serviço à comunidade e de limitação de fim de semana;
III - colaborar na fiscalização do cumprimento das condições da suspensão e do livramento condicional.

Atualmente, o PLDA conta com uma equipe multidisciplinar, composta por profissionais da área da Pedagogia, Psicologia, Serviço Social, Administração e Direito. A articulação do trabalho no PLDA é executada por uma Assistente Social, uma Psicóloga, uma Pedagoga e quatro agentes penitenciários com cargos administrativos. Ainda sobre os profissionais do quadro próprio do Estado, o PLDA é gestado por uma psicóloga que está na direção da instituição e de um dos agentes penitenciários que está na vice-direção.

Do mesmo modo, a instituição também é atendida pelo Programa Universidade Sem Fronteiras promovido pela Universidade Estadual de Londrina por meio do subprograma intitulado "Incubadora dos direitos sociais - Projeto PLDA" representado por uma equipe de profissionais, bolsistas recém-graduados e graduandos dos cursos de Pedagogia, Psicologia, Administração e Direito, bem como, docentes orientadores dos cursos já citados. A equipe do Projeto conta com 9 profissionais recém graduados, entre eles, 2 pedagogas, 3 psicólogas, 3 advogados e 1 administradora. Do mesmo modo, 10 graduandos também compõem a equipe, auxiliando nas atividades diárias de rotina e de atividades específicas das presentes áreas.

Os cumprimentos das penas alternativas fornecidas pelo mesmo se dão na condição de Prestação de Serviço à Comunidade, PrestaçãoPecuniária ${ }^{1}$, Cesta Básica,

\footnotetext{
${ }^{1}$ De acordo com a Lei 9.714 de 1998, em seu Art. 45, "A prestação pecuniária consiste no pagamento em dinheiro à vítima, a seus dependentes ou a entidade pública ou privada com destinação social, de importância fixada pelo juiz, não inferior a 1 (um) salário mínimo nem superior a 360 (trezentos e sessenta) salários mínimos". (BRASIL, 1998)
} 


\section{SEMINÁRIO DE PESQUISA EM CIÊNCIAS HUMANAS - SEPECH \\ Humanidades, Estado e desafios didático-científicos \\ Londrina, 27 a 29 de julho de 2016}

Programa SAIBA ${ }^{2}$, BASTA $^{3}$ e Medida Educativa. Vale ressaltar que, além dessas condições, os assistidos precisam comprovar endereço de residência e, em sua maioria, comprovar emprego, além de uma série de restrições legais que os mesmos têm a cumprir e que são, via de regra, acompanhadas pelo Patronato.

A retomada dos estudos, ou ainda, início desse processo através Medida Educativa, cuja responsabilidade é do setor pedagógico, pode acontecer por três maneiras, sendo elas, a inserção na escola formal com a Educação de Jovens e Adultos (EJA), frequência nos cursos de profissionalização ofertados pelo PLDA ou frequência em cursos de capacitação ou profissionalização em outra instituição de educação formal.

Cabe aqui relatar que a resistência dos assistidos em procurar a EJA é um dos grandes desafios enfrentados pelo setor educacional, no qual os mesmos preferem os cursos ofertados pelo PLDA ou por outra instituição. Este é um dos nossos grandes desafios enquanto equipe pedagógica, por acreditar que, em determinados casos, a retomada dos estudos por meio da frequência na escola formal, seria de grande valia para o sujeito e, sobretudo, o início de um processo de ressocialização. Uma vez que, em entrevistas pedagógicas, os assistidos relatam que a prática criminosa teve correlação com o abandono dos estudos e que a frequência na escola e, sobretudo, o conhecimento adquirido na mesma, iria contribuir para um futuro diferente, com melhores perspectivas pessoais e profissionais, diferente do passado já vivenciado por eles.

\section{MEDIDA EDUCATIVA EXECUTADA EM MEIO ABERTO}

É a partir da audiência admonitória ${ }^{4}$ que é estipulado aos apenados a Medida Educativa como uma condição penal a ser cumprida e, com isso, é incluso na mesma, as horas que serão cumpridas, ou mesmo a frequência somente pela duração do curso. Para isso, o Patronato Penitenciário de Londrina (PLDA), conta com parcerias com outras instituições de Londrina, onde se proporcionam os cursos profissionalizantes, a fim de oferecer a qualificação e profissionalização aos assistidos.

Além dos cursos ofertados pelo PLDA, o setor Pedagógico realiza encaminhamentos para escolas, para que, assim, os assistidos possam retornar ao ensino formal, e, então, gerar a conclusão da educação básica. Um grande número de beneficiários que cumprem a Medida Educativa, ao ingressarem novamente ao ambiente escolar, relata que há certa resistência por parte da escola, em aceitar novamente os mesmos, sendo dificultada sua permanência ou mesmo impedimento em fazer a matrícula. É fundamental, então, que todos obtenham a compreensão de que o Estado deve garantir o direito à educação a todos.

\footnotetext{
${ }^{2}$ O programa SAIBA tem como objetivo diminuir os danos causados pelo uso de drogas ilícitas ao dependente, para que, assim,este sujeito seja capaz de desenvolver suas atividadesprofissionais, sociais e familiares.

3 O programa BASTA tem como objetivo atuar no sentido de minimizar os crimes e conscientizar os mesmos contra a mulher, de forma que futuramente consiga erradica-los.

${ }^{4}$ É uma audiência onde o juiz estabelece as condições individuais de cada apenado para serem cumpridas no regime aberto e/ou semiaberto.
} 


\section{SEMINÁRIO DE PESQUISA EM CIÊNCIAS HUMANAS - SEPECH \\ Humanidades, Estado e desafios didático-científicos \\ Londrina, 27 a 29 de julho de 2016}

Mesmo tendo a Medida Educativa como uma condição penal, muitos destes beneficiários ainda não cumprem esta condição, decorrente a exigência do trabalho, sendo então "[...] preciso que a sociedade incorpore a normalidade e a ressocialização dos presos, uma vez que há, atualmente, muito preconceito acerca dos ex-detentos, principalmente com relações trabalhistas" (BARATTA, 2007, p.4). Logo, é notória, mesmo com barreiras trabalhistas, a opção pelo trabalho é superior à opção do retorno aos estudos.

\section{PESQUISA QUANTITATIVA DESENVOLVIDA}

O setor da Pedagogia do PLDA realizou um levantamento de dados junto ao Sistema de Gestão do Imobiliário do Estado Patrimônio (SISPAT), sistema esse que é utilizado pelo PLDA para a realização do trabalho desenvolvido na instituição. $\mathrm{O}$ SISPAT é um sistema que guarda uma série de informações dos assistidos, estando entre essas informações os dados pertinentes quanto à formação intelectual desses sujeitos.

No ano de 2015, as pedagogas do Projeto "Incubadora dos Direitos Sociais PATRONATO" deram início a uma pesquisa cujo objetivo era realizar um levantamento a fim de obter o número de assistidos que cumprem Medida Educativa na instituição, bem como, o grau de escolaridade dos mesmos. Devido aos inícios de cumprimento de pena em regime aberto e conclusão da mesma por cumprimento integral ou indultos e demais benefícios que levam à conclusão da pena no PLDA serem rotinas do cotidiano do trabalho na instituição, os dados se renovam a cada dia. Portanto, mesmo com a saída do Projeto das pedagogas que iniciaram a coleta de dados, a pesquisa está tendo continuidade no ano de $2016 \mathrm{com}$ as pedagogas ingressantes no Projeto no presente ano.

A pesquisa se deu por meio do levantamento e análise dos dados coletados nas entrevistas iniciais, ou seja, a primeira entrevista realizada no momento em que os assistidos dão início ao cumprimento de pena em regime aberto. $\mathrm{Na}$ área restrita ao setor de Pedagogia no SISPAT foi possível obter a informação do grau de escolaridade de cada assistido que cumpre Medida Educativa, uma vez que esta é uma das perguntas feitas na entrevista inicial. Após o levantamento dos dados, duas tabelas foram feitas, sendo que a primeira continha o nome de todos os assistidos do Regime Aberto e o seu grau de escolaridade. Por sua vez, a segunda tabela é um recorte da primeira, constando nesta, apenas os assistidos do Regime Aberto que possuem a Medida Educativa. A partir dessa tabela foi possível realizar a contagem dos dados e gráficos.

O Patronato Penitenciário de Londrina (PLDA) atualmente, no ano de 2016, oferece assistência a 1531 assistidos. Sendo que desses, 124 possuem Medida Educativa. Como já citado, em agosto de 2015, realizou-se um levantamento de dados a fim de obtermos informações acerca do nível de escolaridade dos egressos do sistema fechado, bem como, dos inicialmente condenados que cumprem pena em regime aberto.

\begin{tabular}{ll}
\hline Grau de Instrução & Total \\
Analfabeto & 28 \\
Ensino Fundamental I & 497 \\
Ensino Fundamental II & 583 \\
\hline
\end{tabular}




\section{SEMINÁRIO DE PESQUISA EM CIÊNCIAS HUMANAS - SEPECH \\ Humanidades, Estado e desafios didático-científicos \\ Londrina, 27 a 29 de julho de 2016}

\begin{tabular}{ll}
\hline Ensino Médio & 578 \\
Ensino Superior & 97 \\
TOTAL & 1784
\end{tabular}

Tabela (1) - Tabela do nível de escolaridade dos assistidos que cumprem pena em Regime Aberto no Patronato Penitenciário de Londrina (PLDA) referente ao mês de Agosto de 2015

Com essa pesquisa foi possível obter os dados de que entre os 1784 sujeitos que compõem os dados dessa amostra no referido período, 97 possuem o Ensino Superior, 578 possuem o Ensino Médio, 583 possuem o Ensino Fundamental II, 497 possuem o Ensino Fundamental I e 28 são analfabetos. Nesse sentido, se partimos do pressuposto de que quem não possui o Ensino Médio, tem um baixo nível de escolaridade, é possível perceber que o nível de escolaridade dos assistidos que cumprem pena em Regime Aberto é baixo, uma vez que mais da metade do número total não possui.

Com o levantamento geral do grau de escolaridade dos assistidos no Patronato Penitenciário de Londrina (PLDA), foi possível realizar outro levantamento, sendo esse, o foco do presente trabalho: o grau de escolaridade dos assistidos que cumprem a Medida Educativa.

Grau de Instrução Total

$\begin{array}{lc}\text { Ensino Fundamental I - Completo } & 14 \\ \text { Ensino Fundamental II - Incompleto } & 36 \\ \text { Ensino Médio - Completo } & 06 \\ \text { Ensino Médio - Incompleto } & 11 \\ \text { Ensino Superior - Completo } & 0 \\ \text { Ensino Superior - Incompleto } & 02 \\ \text { TOTAL } & \mathbf{6 9}\end{array}$

Tabela (2) - Tabela constando o grau de escolaridade dos Assistidos que cumpriam Medida Educativa no último trimestre de 2015.

Sobre a amostragem, é possível afirmar que o grau de escolaridade dos assistidos que cumprem Medida Educativa é baixo, uma vez que até no período do último trimestre de 2015, não havia assistidos que tinham como grau de escolaridade o Ensino Superior completo, sendo passível a conclusão de que dentre um total de 69 assistidos, 67 dos mesmos, não possuem a educação básica concluída, o que aponta para uma população com um baixo nível de escolaridade.

No mês de Janeiro de 2016, o setor da Pedagogia, com o intuito de dar continuidade ao trabalho desenvolvido em 2015, realizou outro levantamento, a fim de obter a informação de quantos assistidos ainda se encontram em descumprimento com a lei com relação à Medida Educativa. Para tanto, realizou-se uma pesquisa com os dados contidos no SISPAT bem como nos arquivos físicos do PLDA do público que possuía Medida Educativa. Nessa pesquisa, foi possível levantar, por meio dos documentos que comprovam a frequência e conclusão em cursos de profissionalização, técnicos e escola regular, os assistidos que cumpriram - concluíram a Medida Educativa, que estavam em situação de cumprimento ou não estavam cumprindo a presente condição que lhes foi imposta, conforme consta nos dados da tabela abaixo. 


\title{
XI SEMINÁRIO DE PESQUISA EM CIÊNCIAS HUMANAS - SEPECH \\ Humanidades, Estado e desafios didático-científicos \\ Londrina, 27 a 29 de julho de 2016
}

MEDIDA EDUCATIVA

TOTAL

\begin{tabular}{l|l} 
CUMPRIRAM INTEGRALMENTE & 08
\end{tabular}

CUMPREM

NÃO CUMPREM

AGUARDAM DOCUMENTOS

37

Tabela (3) - Tabela de análise dos assistidos que possui a Medida Educativa como pena referente ao mês de Janeiro de 2016.

Logo, com base nesta tabela 3, é possível verificar que a questão do descumprimento penal é elevada, uma vez que o numero de quem não cumpre ou aguarda documentação ultrapassa os que cumprem ou estão cumprindo a Medida Educativa.

\section{CONCLUSÃO}

De acordo com as Diretrizes Curriculares Nacionais da Educação Básica, no que se refere à educação em meio à privação de liberdade no sistema prisional, pode-se constatar que

\begin{abstract}
A falta de acesso à educação da população carcerária brasileira tem contribuído para o processo de exclusão social já anterior à prisão: $11,8 \%$ são analfabetos e $66 \%$ não chegaram a concluir o Ensino Fundamental. O tempo que passam na prisão (mais da metade cumpre penas superiores a 9 anos) seria uma boa oportunidade para se dedicar à educação sobretudo quando a maioria $(73,83 \%)$ são jovens com idade entre 18 e 34 anos. Mas o aproveitamento de tal oportunidade ainda não se deu. Apenas $10,35 \%$ dos internos estão envolvidos em atividades educacionais oferecidas nas prisões. (BRASIL, 2013, p. 312 - 313)
\end{abstract}

Dessa forma verifica-se que não só os assistidos que se apresentam no PLDA, mas também os que já passaram pelo regime fechado, apresentam um baixo grau de escolaridade e interesse pelos estudos, este que já os acompanharam muito antes de seus conflitos com a lei, seja pelo meio social ao qual estava inserido ou pelo contato com o crime, e, devido a isso, o setor pedagógico do PLDA vem buscando novas parcerias com instituições em Londrina, com cursos que atendam a maior demanda dos assistidos, que é conseguir um trabalho, proporcionando cursos que complementem suas habilidades ou que the proporcione novos conhecimentos, buscando forma, após resultados positivos em suas vidas, oportunizar um interesse maior pelos estudos, no qual é de fundamental importância em meio à sociedade em que vivemos.

Cabe aqui ressaltarmos que, como profissionais da educação, temos como apropriação a visão de que a Educação é se não o único, o meio mais eficaz de garantia de ressocialização dos sujeitos em conflito com a lei. Uma vez que a mesma induz esses adultos a terem um novo olhar sobre a vida. A educação do egresso e do inicialmente condenado, é, por parte da justiça uma obrigação para com este sujeito, mas, sobretudo, uma preocupação indispensável para com a sociedade. Uma vez que a prisão mostrou-se como o "grande fracasso da justiça penal" como cita Foucault. (Foucault, 1987) 


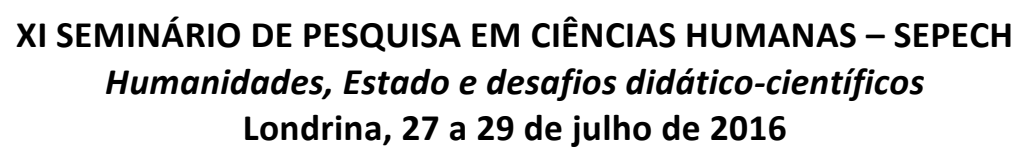

A educação deve trabalhar os conceitos de dignidade, liberdade, cidadania, governo, Estado, miséria, comunidade, entre outros. Ou seja, a educação deve levar o sujeito a perceber e, sobretudo, entender o ato infracional e as consequências do mesmo, como as perdas e o estigma social. É necessário que a educação possibilite a reflexão para que o educando possa desenvolver um olhar de compreensão para com a realidade e, que ao se apropriar dessa compreensão, possa desejar a sua transformação. A educação que defendemos é uma educação que possibilite a autonomia intelectual dos alunos, que ofereça condições para que o aluno possa se apropriar de uma nova visão de mundo. Uma visão humana e social a partir de reflexões.

\section{REFERÊNCIA BIBLIOGRÁFICA}

BRASIL, Presidência da República. Disponível em: $<$ http://www.planalto.gov.br/ccivil_03/leis/L7210.htm>.Acesso em 03 de maio de 2016.

BRASIL, Presidência da República. Disponível em: $<$ http://www.planalto.gov.br/ccivil_03/leis/L9714.htm>. Acesso em 05 de maio de 2016.

BARATTA, Alessandro. Ressocialização ou controle social: uma abordagem crítica da "reintegração social" do sentenciado. Universidade de Saarland, RFA) Alemanha Federal. Disponível em: < http://www. eap. sp. gov.br/pdf/ressocializacao. pdf $>$. Acesso em 18 de Maio, v. 1, 2007.

EDUCAÇAO, Ministério da. Diretrizes Nacionais para a oferta de educação para jovens e adultos em situação de privação de liberdade nos estabelecimentos penais. Disponível em: $<$ http://portal.mec.gov.br/index.php?option $=$ com docman\&view $=$ download\&alias $=155$ 48-d-c-n-educacao-basica-nova-pdf\&Itemid=30192>. Acesso em 21 de abril de 2016.

FOUCAULT, Michel. As palavras e as coisas: uma arqueologia das ciências humanas. São Paulo: Editora Martins Fontes, 1987 